\section{UJMM

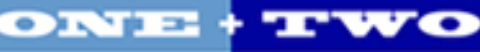

Volume 3 | 2011 Spring

\section{Undergraduate Journal of Mathematical}

Modeling: One + Two

2011

\title{
Retroactive Interference and Forgetting
}

Vinishaa Ankala

University of South Florida

\author{
Advisors: \\ Arcadii Grinshpan, Mathematics and Statistics \\ Andrei Chugunov, Fortis College: Medical Sciences \\ Problem Suggested By: Andrei Chugunov
}

Follow this and additional works at: https://digitalcommons.usf.edu/ujmm

Part of the Mathematics Commons

UJMM is an open access journal, free to authors and readers, and relies on your support:

Donate Now

\section{Recommended Citation}

Ankala, Vinishaa (2011) "Retroactive Interference and Forgetting," Undergraduate Journal of Mathematical Modeling: One + Two: Vol. 3: Iss. 2, Article 4.

DOI: http://dx.doi.org/10.5038/2326-3652.3.2.4

Available at: https://digitalcommons.usf.edu/ujmm/vol3/iss2/4 


\title{
Retroactive Interference and Forgetting
}

\begin{abstract}
Retroactive interference is the amount of information that can be forgotten by a person over time due to newly learned material. In this paper we establish a relationship between the amount of information forgotten by college students while they read and watch television and the time taken to forget it. We equate these numerical equations to solve for the unknown constants. By doing so, we can find the exact equation and also the amount of forgetting information due to retroactive interference.
\end{abstract}

\section{Keywords}

Retroactive Interference, Memory, Exponential Interpolation

\section{Creative Commons License}

(c) $($ ) $\Theta \Theta$

This work is licensed under a Creative Commons Attribution-Noncommercial-Share Alike 4.0 License. 


\section{TABLE OF CONTENTS}

Problem Statement

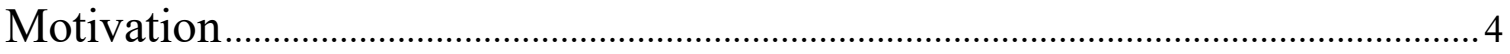

Mathematical Description and Solution Approach ................................................... 4

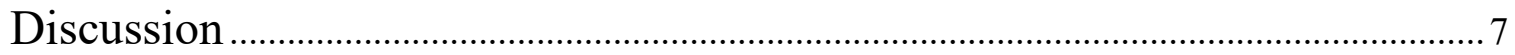

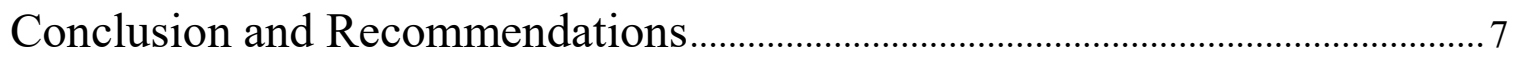

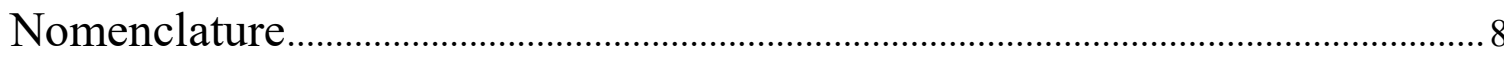

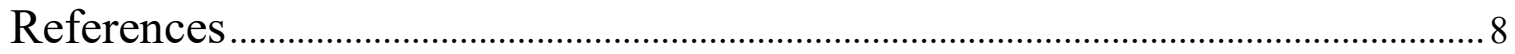

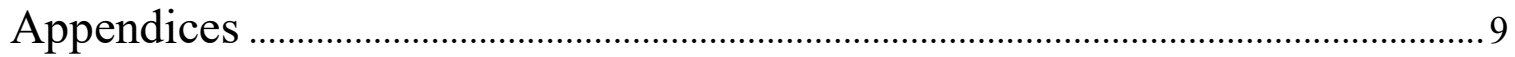




\section{PROBLEM STATEMENT}

Interference theory is a psychological idea which tries to explain some features of memory. It states that interference occurs when the learning of something new causes the forgetting of older material on the basis of competition between the two. There are three main kinds of interference theories: proactive, retroactive and output. Proactive interference occurs when, in any given context, past memories inhibit an individual's full potential to retain new memories. Retroactive interference is a phenomenon that occurs when newly learned information interferes with and impedes the recall of previously learned information. Output interference occurs when the initial act of recalling specific information interferes with the retrieval of the original information. The main assumption of interference theory is that the stored memory is intact but unable to be retrieved due to the competition created by newly acquired or previously learned information.

Recent experiments have shown that retroactive interference has a greater impact on memory storage than proactive interference (Briggs). Retroactive interference occurs when new memories inhibit an individual's full potential to retain old memories. When a person replaces their phone number, the new number becomes completely ingrained in the person's mind making it difficult to recall the old phone number. This competition between the new and old phone numbers is an example of retroactive interference.

We wish to gauge the ability of college students to store memories in an atmosphere that is likely to cause retroactive interference. A previous study (Wixted) suggested that we should expect a forgetting function $F(t)$ of the form

$$
F(t)=a e^{-b t}
$$


which relates the amount information remembered $F(t)$ over time $t$ in minutes. Here $a$ and $b$ are experimentally determined parameters analogous to the $y$-intercept and slope of a line.

\section{MOTIVATION}

People forget many things throughout their daily lives. When information is reinforced over a long period of time it may be easily recalled, however new information quickly begins to interfere with the old memory. Thus if the old memory is not recalled again, it will fade with time and will soon be lost.

Psychologists have been researching interference, especially retroactive interference, for a very long time. Many experiments base performance on how much of memory is retained and how much is forgotten. We seek to determine an equation for calculating retroactive interference by applying some tools from Calculus.

\section{MATHEMATICAL DESCRIPTION AND SOLUTION APPROACH}

We begin by determining the parameters $a$ and $b$ by equating equations with different $t$. From the problem statement we know that $F(t)$ depends on time $t$ according to the equation (1). Retroactive interference can be calculated by measuring the performance of a person so we can assume the performance measure $P$ is equal to $F(t)$, i.e., $P(t)=a e^{-b t}$.

According to John Wixted, if we were given an arbitrary time interval $k$, the ratio of performance at time $t$ to performance at a previous time $t-k$, is equal to the ratio of performance at time $t+k$ to performance at time $t$, i.e., 


$$
\frac{P_{t}}{P_{t-k}}=\frac{P_{t+k}}{P_{t}}
$$

In the continuous case, the derivative with respect to time is $P^{\prime}=-a b e^{-b t}=-b P$, since the derivative of an exponential function is itself exponential. According to an exponential description of forgetting, memory loses a constant proportion of its contents over each fixed time interval.

For the exponential equation $F(t)$, we determined the parameters $a$ and $b$ by conducting an experiment which measured the memory performance of several college students. In this experiment, the students were told to remember 25 different names of people and were asked to write down those names every 15 minutes over a five hour period (for a total of 20 tests). The students were instructed to either watch television or read a book during the intervals between the tests. We noticed that as time passed, the students mixed up the learnt names with the newly learned information from the TV and the book. The results of the experiment are tabulated in Table 1 of Appendix A. We now model their memory performance based on this data.

If the data points $\left\{\left(t_{1}, n_{1}\right),\left(t_{2}, n_{2}\right), \ldots,\left(t_{20}, n_{20}\right)\right\}$ from Table 1 grow exponentially, then the points $\left\{\left(t_{1}, \ln n_{1}\right),\left(t_{2}, \ln n_{2}\right), \ldots,\left(t_{20}, \ln n_{20}\right)\right\}$ will grow linearly and conform to some model

$$
f(t)=A+B t
$$

If $y_{i}=\ln n_{i}$ for each $i=1,2, \ldots, 20$ the discrepancy between the data and the model may be measured as $f\left(t_{i}\right)-y_{i}$. Squaring this discrepancy will weight positive and negative errors equally. Thus the total error between the data and the model is calculated to be

$$
S(A, B)=\sum_{k=1}^{n}\left(f\left(x_{k}\right)-y_{k}\right)^{2}=\sum_{k=1}^{n}\left(\left(A+B x_{k}\right)-y_{k}\right)^{2} .
$$


Minimizing (4) with regard to $A$ and $B$ will yield an optimal linear model. This is accomplished by equating both the partial derivatives of $S(A, B)$ with respect to $A$ and $B$ to zero. The partial derivatives of $S(A, B)$ are

$$
\left\{\begin{array}{l}
S_{A}(A, B)=\sum_{k=1}^{n} 2\left(A+B t_{k}-y_{k}\right) \\
S_{B}(A, B)=\sum_{k=1}^{n} 2 t_{k}\left(A+B t_{k}-y_{k}\right)
\end{array}\right.
$$

Given the data from our experiment (see Table 1 in Appendix A) these partial derivatives evaluate to

$$
\left\{\begin{array}{l}
S_{A}(A, B) \approx 40 A+6,300 B-93.48 \\
S_{B}(A, B) \approx 6,300 A+1,291,500 B-12,552.30
\end{array}\right.
$$

Equating $S_{A}(A, B)=S_{B}(A, B)=0$ yields a system of two equations with two unknown variables. The solution of this system is $A \approx 3.47971$ and $B \approx-0.108826$, i.e.,

$$
f(t)=3.47971-0.007255 t
$$

Thus (7) is the linear model which best fits the points $\left\{\left(t_{1}, \ln n_{1}\right),\left(t_{2}, \ln n_{2}\right), \ldots,\left(t_{20}, \ln n_{20}\right)\right\}$. Therefore, the optimal model for the points $\left\{\left(t_{1}, n_{1}\right),\left(t_{2}, n_{2}\right), \ldots,\left(t_{20}, n_{20}\right)\right\}$ is

$$
P(t)=e^{f(t)} \approx e^{3.48} e^{-0.007 t} \approx 32.45 e^{-0.007 t}
$$

The graphs of $f(t)$ and $P(t)$ appear in Charts 1 and 2 of Appendix B. 


\section{DISCUSSION}

The retroactive interference encountered by the test group may be approximated via equation (8). According to this equation, performance approaches zero as time goes to infinity. If this were true, a person would forget almost everything. Therefore this model should not be used to predict long term memory performance.

It should be noted that this model may not apply to all demographics. Factors such as age may influence the expected performance. This experiment was conducted using college students with ages between 17 and 20, so the model is most reliable for this demographic.

\section{CONCLUSION AND RECOMMENDATIONS}

Newly learned information interferes with previously stored memories. Retroactive interference affects the memory of each person, so it is a topic of great interest to psychologists. In our study, the forgetting due to retroactive interference was not as pronounced as Wixted's previous models (Wixted). However, further research should be done to explore new concepts of memory and retroactive interference. 


\section{NOMENCLATURE}

\begin{tabular}{|c|ll|}
\hline Symbol & Description & Units \\
\hline $\boldsymbol{t}$ & Time & Minutes (min) \\
\hline $\boldsymbol{P}$ & $\begin{array}{l}\text { Performance measure in } \\
\text { terms of names }\end{array}$ & Names \\
\hline
\end{tabular}

\section{REFERENCES}

Briggs, G. E. " Acquisition, extinction, and recovery functions in retroactive inhibition." Journal of Experimental Psychology (1954).

Tarnow, Eugen. "Retroactive Interference." Medscape General Medicine 72005.

Underwood, Benton. "Retoractive Interference with Increased Recall Time." The American Journal of Psychology (1950).

Wixted, John. "The Psychology and Neuroscience of Forgetting."Annual Review of Psychology. 55 (2004): 235-269. 


\section{APPENDICES}

\section{APPENDIX A - TABLES}

\begin{tabular}{|c|c|c|c|c|c|}
\hline \multirow[b]{2}{*}{$\begin{array}{c}\text { Test Period } \\
k\end{array}$} & \multirow[b]{2}{*}{$\underset{t_{k}}{\operatorname{Time}}$} & \multicolumn{2}{|c|}{ Experiment Data } & \multicolumn{2}{|c|}{ Best-Fit Model } \\
\hline & & $\begin{array}{c}\text { Names Recalled } \\
\boldsymbol{n}_{\boldsymbol{k}}\end{array}$ & $\begin{array}{c}\ln n_{k} \\
y_{t}\end{array}$ & $\begin{array}{c}\text { Linear } \\
f\left(t_{k}\right)\end{array}$ & $\begin{array}{c}\text { Exponential } \\
F\left(t_{k}\right)\end{array}$ \\
\hline 1 & 15 & 24 & 3.17805 & 3.37089 & 29.10 \\
\hline 2 & 30 & 22 & 3.09104 & 3.26206 & 26.10 \\
\hline 3 & 45 & 21 & 3.04452 & 3.15323 & 23.41 \\
\hline 4 & 60 & 18 & 2.89037 & 3.04441 & 21.00 \\
\hline 5 & 75 & 15 & 2.70805 & 2.93558 & 18.83 \\
\hline 6 & 90 & 17 & 2.83321 & 2.82676 & 16.89 \\
\hline 7 & 105 & 16 & 2.77259 & 2.71793 & 15.15 \\
\hline 8 & 120 & 15 & 2.70805 & 2.60911 & 13.59 \\
\hline 9 & 135 & 11 & 2.39790 & 2.50028 & 12.19 \\
\hline 10 & 150 & 15 & 2.70805 & 2.39146 & 10.93 \\
\hline 11 & 165 & 12 & 2.48491 & 2.28263 & 9.80 \\
\hline 12 & 180 & 13 & 2.56495 & 2.17381 & 8.79 \\
\hline 13 & 195 & 10 & 2.30259 & 2.06498 & 7.89 \\
\hline 14 & 210 & 11 & 2.39790 & 1.95615 & 7.07 \\
\hline 15 & 225 & 10 & 2.30259 & 1.84733 & 6.34 \\
\hline 16 & 240 & 8 & 2.07944 & 1.73850 & 5.69 \\
\hline 17 & 255 & 3 & 1.09861 & 1.62968 & 5.10 \\
\hline 18 & 270 & 3 & 1.09861 & 1.52085 & 4.58 \\
\hline 19 & 285 & 4 & 1.38629 & 1.41203 & 4.10 \\
\hline 20 & 300 & 2 & 0.69315 & 1.30320 & 3.68 \\
\hline
\end{tabular}

Table 1: Amount of information memorized in terms of names of people. 


\section{APPENDIX B - CHARTS}

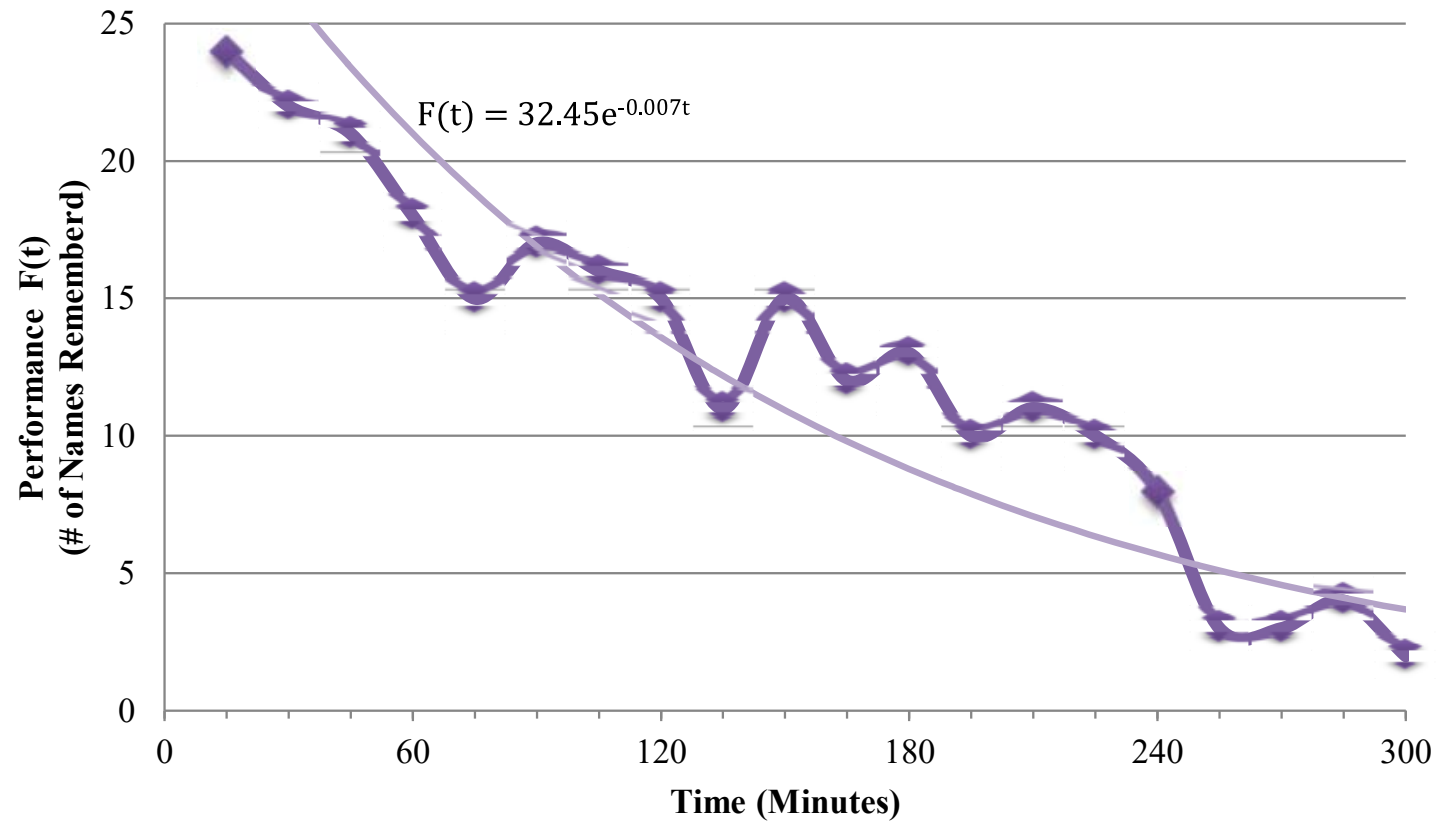

Chart 1: College students were asked to recall 25 names from a list at 15 minute time intervals.

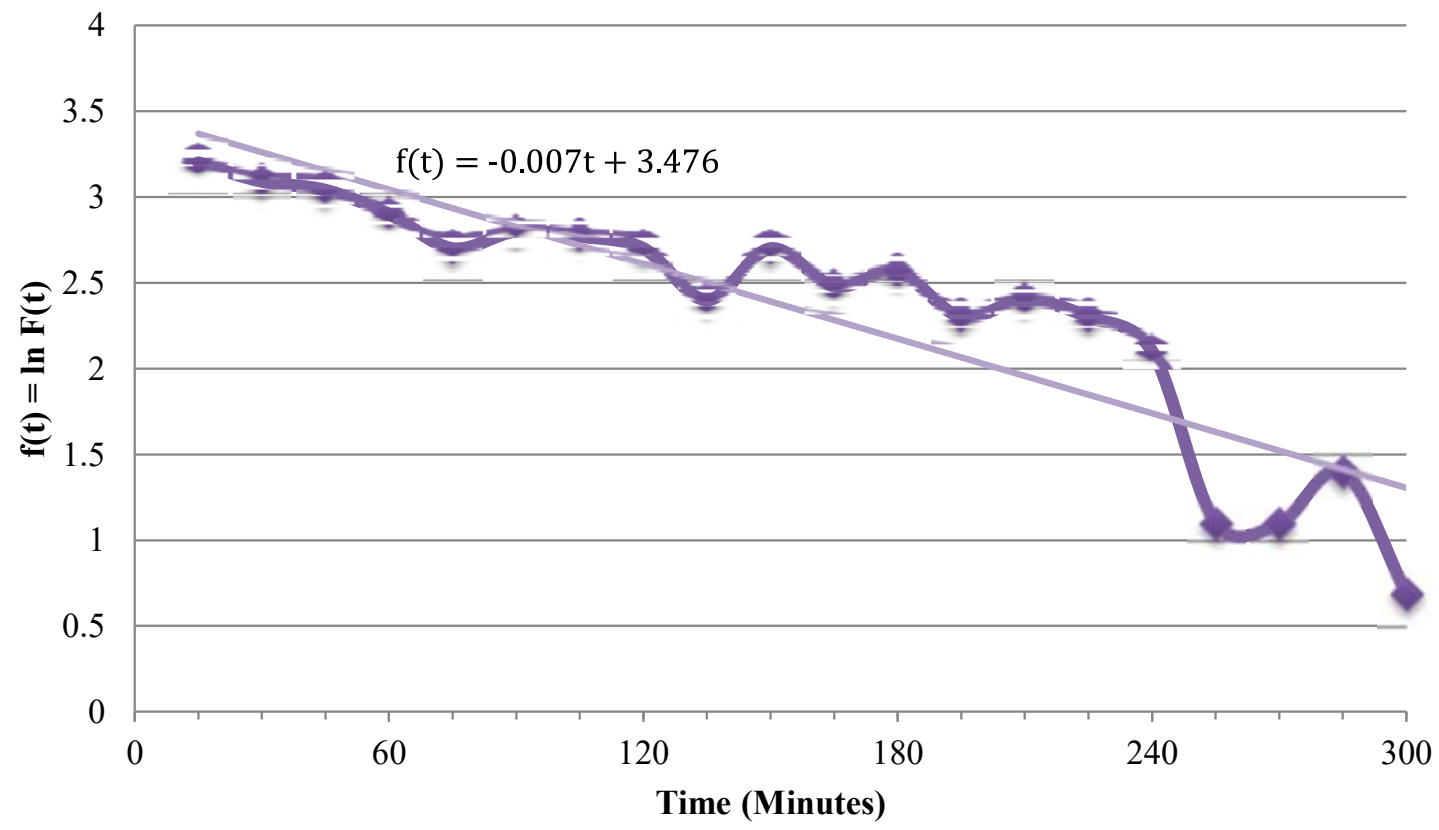

Chart 2: Natural log of the memorized names over time in minutes 